\title{
A nonlinear interaction event between a 16-day wave and a diurnal tide from meteor radar observations
}

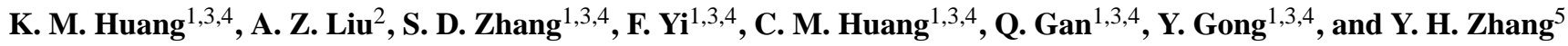 \\ ${ }^{1}$ School of Electronic Information, Wuhan University, Wuhan, China \\ ${ }^{2}$ Department of Physical Sciences, Embry-Riddle Aeronautical University, Daytona Beach, Florida, USA \\ ${ }^{3}$ Key Laboratory of Geospace Environment and Geodesy, Ministry of Education, Wuhan, China \\ ${ }^{4}$ State Observatory for Atmospheric Remote Sensing, Wuhan, China \\ ${ }^{5}$ College of Hydrometeorology, Nanjing University of Information Science and Technology, Nanjing, China
}

Correspondence to: S. D. Zhang (zsd@whu.edu.cn)

Received: 2 July 2013 - Revised: 10 October 2013 - Accepted: 11 October 2013 - Published: 21 November 2013

\begin{abstract}
Relative to extensive studies of interactions between the quasi 2-day wave and tides, nonlinear interaction of the 16-day wave with tides was reported less, in particular interaction with the diurnal tide. We present an observational study of a possible nonlinear interaction event between the 16-day wave and the diurnal tide based on meteor radar measurement at Maui. An obvious 16-day wave can be observed from raw wind data. Its maximum meridional wind amplitude can attain $18.0 \mathrm{~m} \mathrm{~s}^{-1}$ at a height of $92 \mathrm{~km}$ during the time of our attention, which is larger than that in previous reports. Sum and difference interactions between the 16-day wave and the diurnal tide are observed to have rather different intensities. Because sum nonlinear interaction is very intense, the secondary sum wave with a period of $22.59 \mathrm{~h}$ is stronger than the diurnal tide. However, weak spectrum of the secondary difference wave is hardly identified. The beat of the diurnal tide with the secondary sum wave leads to substantial modulation of the diurnal tide at a period of 16 days. Moreover, this strong secondary sum wave further interacts with the 16-day wave to generate a new secondary wave with a period of $21.33 \mathrm{~h}$. Such an interaction may be also regarded as a third-order nonlinear interaction between the 16-day wave and the diurnal tide with two-step interaction. Hence, the third-order nonlinear interaction between planetary waves and tides may occur significantly in the MLT region.
\end{abstract}

Keywords. Meteorology and atmospheric dynamics (Middle atmosphere dynamics; Waves and tides)

\section{Introduction}

Atmospheric waves, including tidal, planetary and gravity waves, play important roles in determining large-scale circulation and thermal structure of the mesosphere and lower thermosphere (MLT) because these waves transport energy and momentum from one atmospheric layer to another, leading to global redistribution of atmospheric energy and momentum and coupling among various atmospheric layers. As the atmospheric density decreases, amplitudes of atmospheric waves propagating into the MLT increase, and then many complex nonlinear processes of waves may occur in the MLT region, for example, nonlinear coupling between waves and background flow (Dickinson, 1969; Hartmann et al., 1984; Miyahara et al., 1993; Huang et al., 2010), nonlinear interactions among tidal, planetary and gravity waves (Fritts and Vincent, 1987; Stenflo, 1994; Nakamura et al., 1997; Jacobi et al., 1998, 2006; Liu and Hagan, 1998; Beard et al., 1999; Pancheva, 2000, 2006; Pancheva et al., 2000a, b; Liu et al., 2008; Stenflo and Shukla, 2009; Huang et al., 2009, 2013a), and breaking due to their amplitudes exceeding the instability thresholds (Lindzen, 1981; Leovy et al., 1985; Polvani and Saravanan, 2000; Xu et al., 2006). Hence, the activities of these waves dominate the local dynamics of the MLT region.

Planetary waves are global scale oscillation. Theoretical work indicates that planetary waves observed in the MLT region correspond to a series of classical westward propagating Rossby normal modes $(s, n-s)$ ( $s$ is the zonal wavenumber and $n$ is the meridional index) with periods of about $2,5,10$ 
and 16 days derived from Laplace's tidal equation under an isothermal atmosphere (Salby, 1981, 1984). In a realistic atmosphere, periods of these normal modes may be modified due to Doppler shifting by background wind fields. Planetary waves are generally driven by flow over orography and differential heating between land and sea. Because wave propagation in the vertical direction depends on their intrinsic phase velocity (Charney and Drazin, 1961), planetary waves originating from the lower atmosphere may propagate upward to the MLT region under certain atmospheric conditions (Dickinson, 1968).

The 16-day wave is identified with the second symmetric $s=1$ normal mode $(1,3)$ (Salby, 1981, 1984). The climatology of the 16-day wave has been extensively revealed in wind, temperature and geopotential height by ground-based and satellite-borne measurements (Forbes and Leveroni, 1992; Williams and Avery, 1992; Espy and Witt, 1996; Espy et al., 1997; Mitchell et al., 1999; Luo et al., 2000, 2002a, b; Namboothiri et al., 2002; Jiang et al., 2005; Lima et al., 2006; Day and Mitchell, 2010; McDonald et al., 2011). Since the 16-day wave has a small phase speed, its vertical propagation is strongly dependent on the background flow. It can be trapped by the strong westward flow in the summer stratosphere, but can propagate into the MLT region through weak eastward wind in late winter or early spring (Forbes et al., 1995; Miyoshi, 1999; Luo et al., 2002a, b; Namboothiri et al., 2002). Hence, the 16-day wave is prominent in the MLT region from October to April. Its zonal wind amplitude in winter can exceed $10 \mathrm{~m} \mathrm{~s}^{-1}$, and is larger than the meridional one on average. However, it is often observed that its meridional component is stronger than the zonal one (Luo et al., 2002a, b; Namboothiri et al., 2002; Day and Mitchell, 2010). In the mesopause region, the 16-day wave usually shows a rather long vertical wavelength or a standing wave structure with slow or no obvious phase variation with height (Luo et al., 2002a, b; Namboothiri et al., 2002; Jiang et al., 2005; Lima et al., 2006; McDonald et al., 2011). The observed summer 16-day wave is suggested to be ducted to the summer hemisphere from the winter hemisphere along eastward wind fields, or is locally generated in the MLT due to dissipation of gravity waves modulated by the 16-day wave in the lower atmosphere (Forbes et al., 1995; Miyoshi, 1999).

Atmospheric tides are global scale perturbations with periods that are harmonics of a solar day. Main excitation sources of tides are absorption of solar radiation and latent heat release in the troposphere and stratosphere. Migrating tides are a subset of tides propagating westward synchronously with the Sun, of which the migrating diurnal $(s=-1)$ and semidiurnal $(s=-2)$ tides are the most prominent tidal components in the MLT region (Liu et al., 2004; Li et al., 2009; $\mathrm{Xu}$ et al., 2009; Lu et al., 2011; Jacobi, 2012). Tides in the MLT region exhibit substantial seasonal variability in amplitude and phase, which is attributed to solar heating and background wind fields (McLandress, 2002). Besides, it is regularly observed that the tidal amplitudes are modulated at periods of planetary wave. Nonlinear interaction between planetary waves and tides is regarded as important mechanisms responsible for this modulated variability of tides (Kamalabadi et al., 1997; Jacobi et al., 2001; Beard et al., 1999; Pancheva, 2000, 2006; Pancheva et al., 2000b, 2002; Zhou et al., 2000; Pancheva and Mitchell, 2004; Liu et al., 2007; Kumar et al., 2008; Huang et al., 2012). In nonlinear processes, interacting tidal and planetary waves can generate two secondary waves whose frequencies and wave numbers are the sum and difference of those of the primary waves, and then these secondary waves beat tide to cause tidal modulation at a period of planetary waves (Teitelbaum and Vial, 1991).

Nonlinear interaction between planetary waves and tides has attracted close attention. It can be noted that previous studies mainly focused on nonlinear interactions of the quasi 2-day wave with the diurnal and semidiurnal tides based on observations and models (e.g., Harris and Vincent, 1993; Walterscheid and Vincent, 1996; Kamalabadi et al., 1997; Thayaparan et al., 1997; Jacobi et al., 2001; Beard et al., 1999; Norton and Thuburn, 1999; Palo et al., 1999, 2007; Pancheva, 2000, 2006; Pancheva et al., 2000b, 2002; Zhou et al., 2000; Gurubaran et al., 2001; Pancheva and Mitchell, 2004; Liu et al., 2007; Kumar et al., 2008; Hecht et al., 2010; McCormack et al., 2010; Babu et al., 2011; Chang et al., 2011; Yue et al., 2012; Huang et al., 2013b). Relative to the extensive studies of interaction of the quasi 2-day wave and tides, nonlinear interaction of the 16-day wave with tides has drawn little attention, possibly due to the requirement of long temporal coverage of observational data. By using zonal and meridional winds observed by radar at the middle and high latitudes in two hemispheres, Pancheva (2000) and Pancheva et al. (2002) demonstrated that there was considerable modulation of amplitudes of the semidiurnal tide at periods of planetary waves, particularly evident at 10- and 16-day periods. Their analysis also indicates that the nonlinear interaction between the semidiurnal tide and the 16-day wave was much stronger than those between the diurnal tide and the 16-day wave. Pancheva and Mitchell (2004) studied the interaction of the semidiurnal tide with the 5-, 10- and 16day waves in detail, proving the validity of frequency, phase, and vertical wavenumber relationships between the primary waves (the semidiurnal tide and the planetary waves) and secondary waves based on meteor radar observations over Esrange $\left(68^{\circ} \mathrm{N}, 21^{\circ} \mathrm{E}\right)$. In addition, the quasi 2-day wave in summer is often found to be modulated by the 16-day wave in the MLT region, and bispectrum analysis shows nonlinear interaction between the quasi 2-day and 16-day waves responsible for this periodic variability of the quasi 2-day wave (Jacobi et al., 1998; Pancheva et al., 2000a).

In this paper, we present an interaction event of the 16-day wave and the diurnal tide based on Maui meteor radar observations at the low latitude $\left(20.8^{\circ} \mathrm{N}\right)$. Huang et al. (2013a) have confirmed that the third-order nonlinear interaction of atmospheric gravity waves can take place effectively in the MLT region. In this strong interaction event, we will reveal a 
significant cascade of nonlinear interactions between the 16day wave and the diurnal tide, which may also be regarded as a third-order nonlinear interaction with a two-step interaction (Phillips, 1960). In the next section, a brief description of meteor radar and observational data is provided. The characteristics of the 16-day wave are analyzed in Sect. 3. In Sect. 4, nonlinear interaction between the 16-day wave and the diurnal tide is discussed. Section 5 presents tidal modulation derived from beat frequency due to linear superposition of the diurnal tide and the secondary wave. Finally, the summary is given in Sect. 6 .

\section{Meteor radar observation}

The Maui meteor radar is located in Kihei on Maui, Hawaii, at $20.8^{\circ} \mathrm{N}, 156.4^{\circ} \mathrm{W}$. The system used an all-sky interferometric meteor radar (SKiYMET) (Hocking et al., 2001) operating at $40.92 \mathrm{MHz}$. The meteor trails were illuminated by a three-element Yagi antenna directed toward the zenith with an average transmitted power of approximately $170 \mathrm{~W}$, which resulted from a $13.3 \mu$ s pulse length, $6 \mathrm{~kW}$ peak envelope power and a $466 \mu$ s interpulse period. The meteor trail reflections were detected by five three-element Yagi antennas oriented along two orthogonal baselines. A center antenna was at the intersection of the two orthogonal baselines, and four outer antennas were separated from the center antenna by 1.5 and 2.0 wavelengths. The receiving antennas were sampled every $13.3 \mu \mathrm{s}$, resulting in a $2 \mathrm{~km}$ range resolution. At each altitude, the meteors detected within a $4 \mathrm{~km}$ bin were used for the least square fit, but with a weight profile that is triangular with peak at the center altitude, and decreases to zero and $\pm 2 \mathrm{~km}$ above and below. The hourly vertical profiles were oversampled at a $1 \mathrm{~km}$ height interval in the range from 80 to $100 \mathrm{~km}$. The measurement errors are typically $3-4 \mathrm{~m} \mathrm{~s}^{-1}$ in the wind data. A detailed description of the meteor radar system and the horizontal wind calculation can be found in previous works (Franke et al., 2005; Lu et al., 2011).

These wind data for the 32 days from 10 November to 11 December 2003 are used to investigate the nonlinear interaction between the 16-day wave and the diurnal tides in this study. The data gaps are few, and the maximum length of the data gaps is $4 \mathrm{~h}$. The gaps are simply filled by linear interpolation. We pay attention to the diurnal tide and the 16-day wave with periods much larger than $4 \mathrm{~h}$, thus the influence of interpolation on our results is small.

\section{16-day wave}

Figure 1 shows the observed meridional (positive northward) wind at heights of 90-95 km for the 32 days from 10 November to 11 December 2003. 10 November is marked as day 1 . During this period, the meridional wind attains the maximum magnitude of about $100 \mathrm{~m} \mathrm{~s}^{-1}$, and shows intense wave ac-

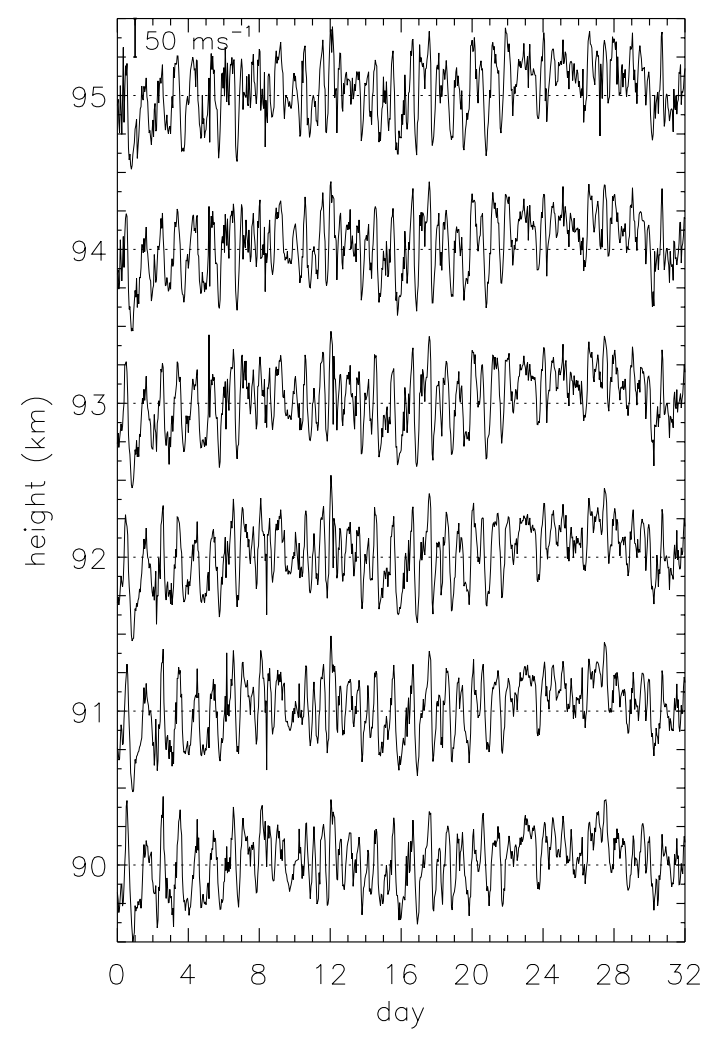

Fig. 1. Meridional wind at the heights of $90-95 \mathrm{~km}$ for 32 days from 10 November to 11 December 2003.

tivities with different time scales. A strong 16-day wave that lasts for 32 days can clearly be seen from the raw data.

In order to highlight the structure characteristic of the 16day wave, a wavelet analysis is used to determine its dominant period and amplitude variation with time (Pancheva et al., 2000a). The Morlet wavelet is applied because of its simplicity and resemblance to the wave packet. The Morlet wavelet consists of a plane wave modulated by a Gaussian envelope $\psi(t)=\pi^{-1 / 4} e^{-j \omega_{0}(t-\tau) / s} e^{-(t-\tau)^{2} / 2 s^{2}}$, where $\tau$ is the time location of the localized transform and $s$ is the scale factor that dilates or contracts the wavelet scale; $\omega_{0}$ is the non-dimensional frequency, here taken to be 6 , to satisfy the admissibility condition. By changing the scale $s$ and moving along the time, the local amplitudes of oscillations at selected periods are calculated. Figure 2 shows the 16day wave structure in the meridional wind derived from the wavelet analysis. It can be noted that the dominant oscillation period is 16 days during 32 days. The maximum amplitude slightly increases from $16.5 \mathrm{~m} \mathrm{~s}^{-1}$ at $90 \mathrm{~km}$ to $18.0 \mathrm{~m} \mathrm{~s}^{-1}$ at $92 \mathrm{~km}$, and then decreases to $14.5 \mathrm{~m} \mathrm{~s}^{-1}$ at $95 \mathrm{~km}$. Relative to the amplitudes of $5-15 \mathrm{~m} \mathrm{~s}^{-1}$ from radar observations during many years in previous reports (Luo et al., 2002a, b; Namboothiri et al., 2002; Lima et al., 2006; Day and Mitchell, 2010), such amplitude values are large, indicating that this 16-day wave is robust. A similar analysis of the zonal wind 


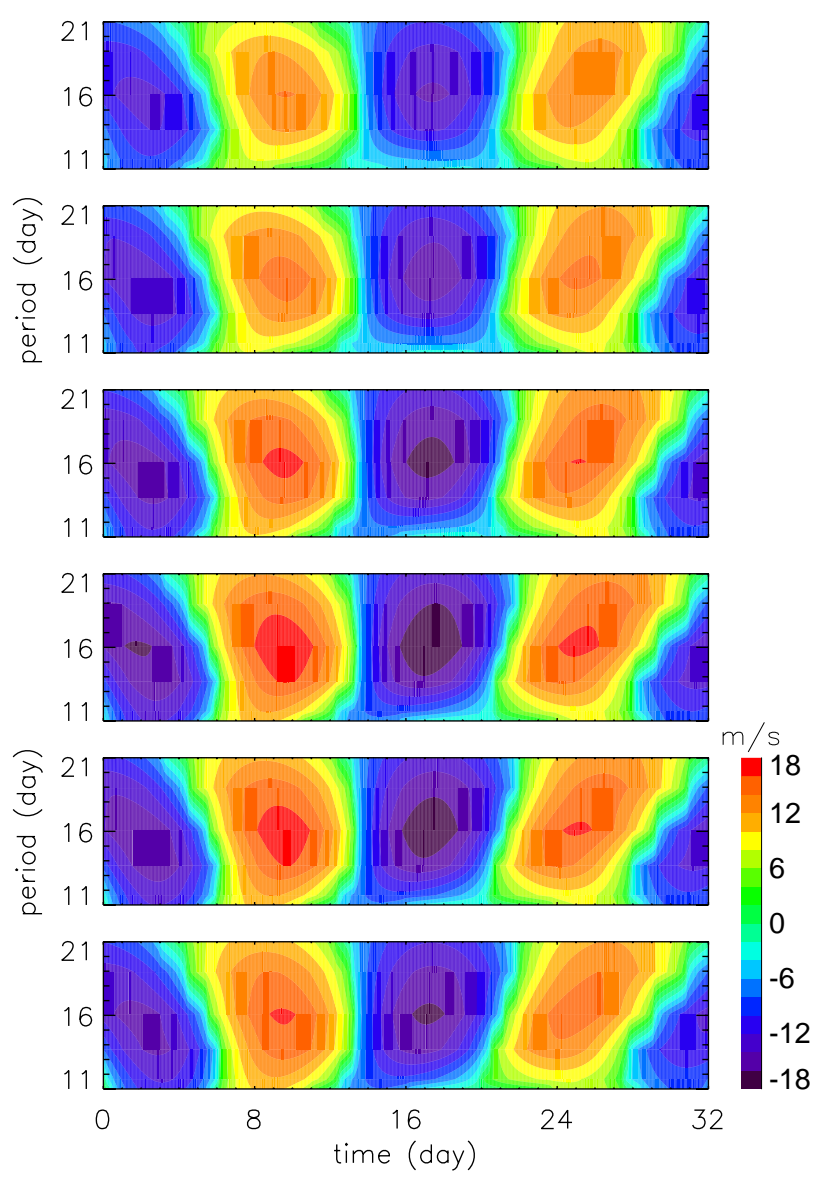

Fig. 2. 16-day wave perturbations derived from the wavelet analysis. The panels from bottom to top represent the results at $90-95 \mathrm{~km}$.

(not presented) shows that the zonal wind amplitude, with values of several $\mathrm{m} \mathrm{s}^{-1}$, is much weaker than the meridional one. This phenomenon is also found at times, although the meridional component is weaker than the zonal one on average (Luo et al., 2002a, b; Namboothiri et al., 2002; Jiang et al, 2005). One can observe that the 16-day wave has an almost constant phase with height variation. This means a very long vertical wavelength, which is consistent with previous studies (Luo et al., 2002a, b; Namboothiri et al., 2002; McDonald et al., 2011). The zonal wavenumber of the 16day wave cannot be deduced from the observations at a single station. The TIMED/SABER temperature observations are used to compute the frequency-wavenumber spectrum, and the method of the spectral analysis is described in detail by Salby $(1982 a, b)$. Here, the TIMED/SABER temperature data in the zone of $18.8-22.8^{\circ} \mathrm{N}$ from 2 November to $19 \mathrm{De}-$ cember 2003 is used to calculate the zonal wavenumber of the 16-day wave. Figure 3 shows the normalized frequencywavenumber spectrum with the corresponding period longer than 12.5 days at $90 \mathrm{~km}$. In Fig. 3, the negative and positive frequencies denote the westward and eastward propagations,

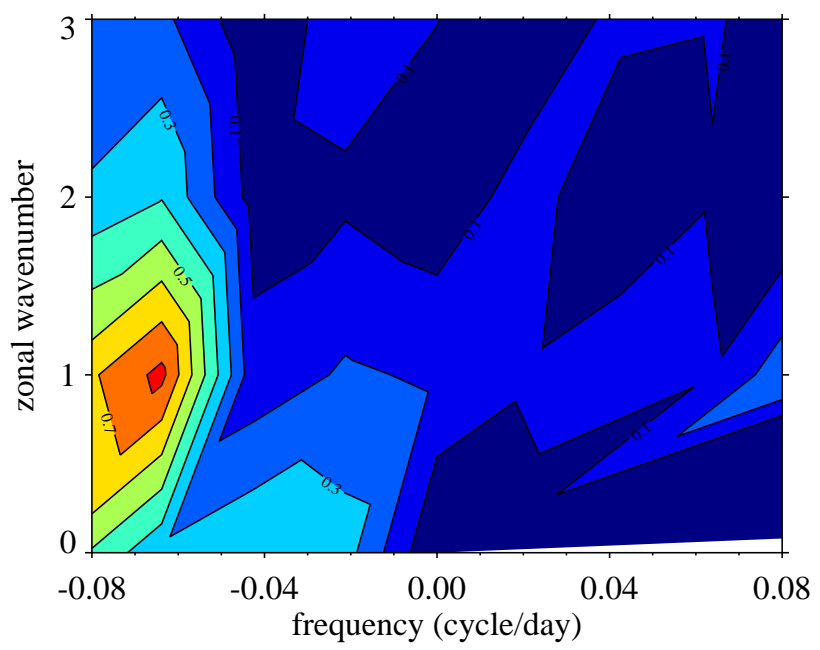

Fig. 3. Normalized frequency-wavenumber spectrum based on the TIMED/SABER temperature observations at $90 \mathrm{~km}$ in the zone of $18.8-22.8^{\circ} \mathrm{N}$ for 48 days from 2 November to 19 December 2003. The negative and positive frequencies denote the westward and eastward propagations, respectively.

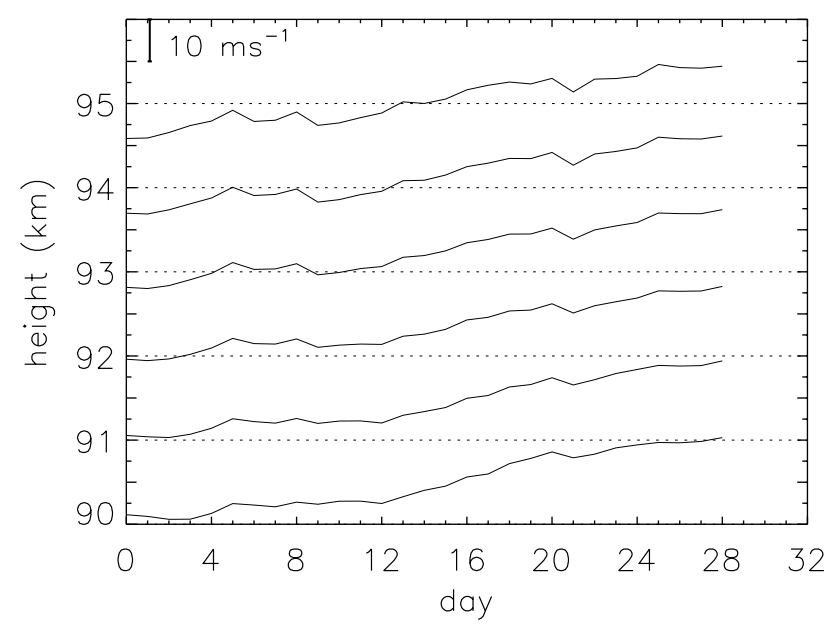

Fig. 4. Background wind derived from moving averaged velocities using a 16-day sliding window with a 1-day increment.

respectively. Hence, there is a westward propagating 16-day component with a zonal wavenumber $s=1$ in the temperature observations. The result is in good agreement with the theoretical prediction and previous observations of wind and temperature (Salby, 1981, 1984; Williams and Avery, 1992; Forbes et al., 1995; Espy et al., 1997).

Figure 4 shows the 16-day running averaged zonal wind with 1-day increment starting on 2 November 2003. The time at the center of the window is denoted as the time of the running average. The background wind after day 28 cannot be obtained because of missing data for several days. Considering that a 16-day smoothing can roughly suppress the 16-day wave, the diurnal and the semidiurnal tides, the 
averaged wind may approximately be regarded as the background zonal wind. Because the amplitude of the 16-day wave can vary with time, this smoothing cannot completely suppress the 16-day wave. Hence, the background wind still shows a slight 16-day oscillation; however, the influence of this small oscillation on the background wind is very weak. It can be seen that the background zonal winds show an approximately linear increase with time, but a decreased tendency with altitude. The velocity of the background wind at $90 \mathrm{~km}$ grows from $2.3 \mathrm{~m} \mathrm{~s}^{-1}$ on day 1 up to $20.6 \mathrm{~m} \mathrm{~s}^{-1}$ on day 28. The background wind decreases with increasing altitude. It reverses to be westward at $93 \mathrm{~km}$, and reaches $-8.3 \mathrm{~m} \mathrm{~s}^{-1}$ at $95 \mathrm{~km}$. At Maui latitude of $20.8^{\circ} \mathrm{N}$, the westward phase speed of the 16-day wave is calculated to be $27.2 \mathrm{~m} \mathrm{~s}^{-1}$. Hence, the background flow at these heights is appropriate for the propagation of the 16-day wave, which is in agreement with the results of the theoretical and previous observational studies (Charney and Drazin, 1961; Luo et al., 2002a, b; Namboothiri et al., 2002). The reverse of the background zonal wind at $93 \mathrm{~km}$ may be a possible reason for the wave amplitude decrease starting at $93 \mathrm{~km}$.

\section{Nonlinear interaction with diurnal tide}

This nonlinear interaction is first examined via their spectra. We make a discrete Fourier transform (DFT) on the meridional wind at the heights of $90-95 \mathrm{~km}$, and the frequency spectra are shown in Fig. 5. There are four strong spectral components with confidence level larger than $95 \%$, which correspond to periods of 16 days, 24, 22.59 and $12 \mathrm{~h}$. According to the theory of tidal interaction with planetary waves proposed by Teitelbaum and Vial (1991), when the 16-day wave interacts with the diurnal tide, the secondary sum and difference waves have periods of 22.59 and $25.6 \mathrm{~h}$. Fig. 5 shows that the secondary sum wave with a period of $22.59 \mathrm{~h}$ is rather strong, but the secondary difference wave corresponding to the period of $25.6 \mathrm{~h}$ is quite weak, and its weak spectral peak appears only at heights of 90-92 km. In addition, an interesting phenomenon can be observed from Fig. 5. Above $93 \mathrm{~km}$, the spectral magnitude of the $22.59 \mathrm{~h}$ wave is obviously stronger than that of the diurnal tide, and a new spectral component with a period of $21.33 \mathrm{~h}$ appears and can reach a confidence level of $85 \%$ at 94 and $95 \mathrm{~km}$. It is noted that the frequency of the $21.33 \mathrm{~h}$ wave equals the sum of those of the 22.59-h and the 16-day waves. Hence, the strong 22.59-h wave generated through the nonlinear interaction between the 16-day wave and the diurnal tide further interacted with the 16-day wave to excite the 21.33 -h wave. This is also regarded as a third-order interaction of the 16-day wave with the diurnal tide with a two-step interaction (Phillips, 1960; Rüster, 1994; Huang et al., 2013a). A similar two-step interaction between the quasi 2-day wave and tides proposed by Walterscheid and Vincent (1996) was used to account for the rapid amplification and phase locking of the quasi 2-day

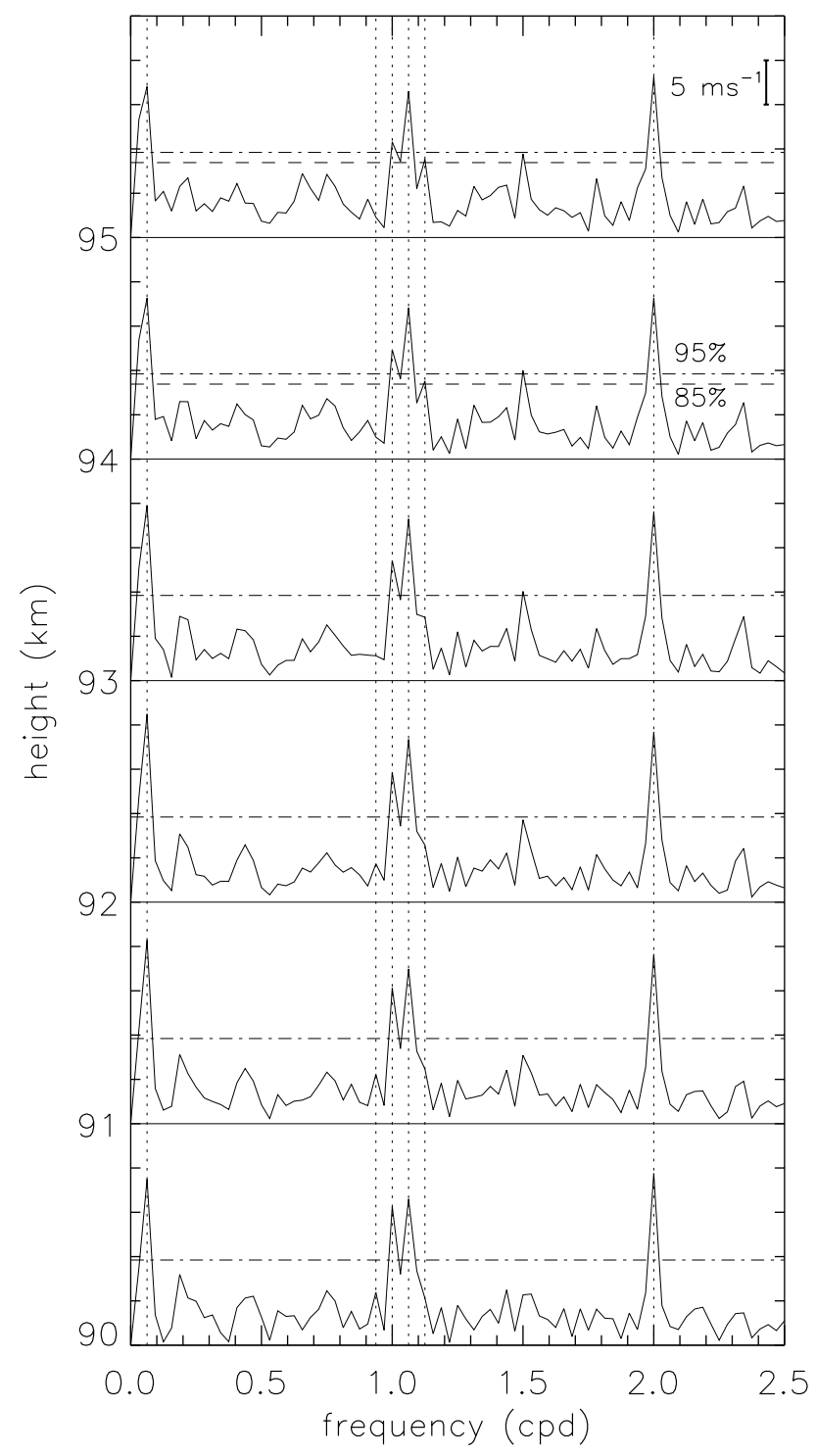

Fig. 5. Fourier spectra of meridional wind during 32 days. The dotted vertical lines from left to right denote spectral components of $0.0625,0.9375,1.0,1.0625$ and $1.125 \mathrm{cpd}$ corresponding to periods of 16 days, $25.6,24,22.59,21.33$ and $12 \mathrm{~h}$, respectively. The dashdotted and dashed (upper two panels) horizontal lines indicate the confidence levels of 95 and $85 \%$, respectively.

wave observed in the Southern Hemisphere. The evidence for this coupling in observational and assimilated data was found (Pancheva, 2006; McCormack et al., 2010), and nonmigrating diurnal $s=-6$ tide created in the first-step interaction was identified in modeling studies (Palo et al., 1999; Chang et al., 2011). Therefore, in this event, the substantial interactions between the 16-day wave and the diurnal tide took place not only at the second order, but also the third order. One can see from Fig. 5 that there is no significant sum and difference spectrum peak of the 16-day wave and the semidiurnal tide. Hence, we do not observe the interaction between the 
16-day wave and the semidiurnal tide. This event is different from the frequently observed results in that the interaction of the 16-day wave with the semidiurnal tide was much stronger than those with the diurnal tide (Pancheva et al., 2000b, 2002; Pancheva and Mitchell, 2004).

The bispectrum analysis is extensively applied to detecting the wave-wave nonlinear interaction since it reveals the phase information of the spectra (Kim and Powers, 1979). A strong bispectral amplitude indicates the quadratic phase coupling arising from the wave-wave interaction. Because of the 16-day wave involved in the analyzed spectra, we extend the 32-day meridional wind data by 4 days backward and forward, respectively, and divide the 40-day wind data into 65 segments by a 32-day sliding window with a 3-h shifting step. The bispectrum of each segment is calculated, and the contribution of spontaneously excited modes to the calculated bispectrum is eliminated by averaging these bispectrum estimates across all 65 segments. The averaged bispectrum is normalized by the maximum spectral magnitude, leading to relative bispectrum amplitude between 0 and 1 .

Figure 6 shows the normalized bispectra in the height range from 90 to $95 \mathrm{~km}$. We use the frequencies $\left(\omega_{i}, \omega_{j}\right.$, $\omega_{i+j}$ ) of the interacting wave triad to denote the bispectral peak, where $\omega_{i}$ and $\omega_{j}$ are the spectral components marked in the horizontal and vertical axes in Fig. 6, and $\omega_{i}+\omega_{j}=\omega_{i+j}$. Notice that the wave with frequency $\omega_{i+j}$ represents a generated wave in the sum interaction, but a primary wave in the difference interaction. At the heights of $90-95 \mathrm{~km}$, the strongest bispectrum is at $(1.0,0.0625,1.0625) \mathrm{cpd}$, which shows a strong nonlinear interaction among the diurnal tide and the 16-day and 22.59-h waves. A weak peak at $(0.9375$, $0.0625,1.0)$ cpd appears only at 90-93 km, indicating a weak difference interaction between the 16-day wave and the diurnal tide. Hence, the bispectral results confirm the nonlinear sum and difference interactions between the 16-day wave and the diurnal tide with different magnitudes.

In Fig. 6, a bispectrum speak at $(1.0625,0.0625$, $1.125)$ cpd appears at $92 \mathrm{~km}$, and increases to a considerable level at $95 \mathrm{~km}$, which suggests that the 21.33 -h wave is produced through the sum interaction between the 16-day wave and the 22.59-h wave. The excitation of the 22.59-h wave through the sum interaction between the 16-day wave and the diurnal tide demonstrates that this is indeed a two-step, third-order interaction.

When the 16-day wave interacts with the diurnal tide, the frequencies of both the secondary sum and difference waves are quite close to the frequency of the diurnal tide because relative to the diurnal tide, the 16-day wave has a very low frequency. The linear superposition of the secondary waves and the diurnal tide leads to the modulation of the tidal amplitude at period of 16 days due to their beat frequency (Teitelbaum and Vial, 1991). Here, we extract the diurnal tide from the 32-day meridional wind using band-pass filtering with high and low cut-off frequencies corresponding to periods at 21.33 and $27.43 \mathrm{~h}$. Figure 7 shows the filtered perturbations.
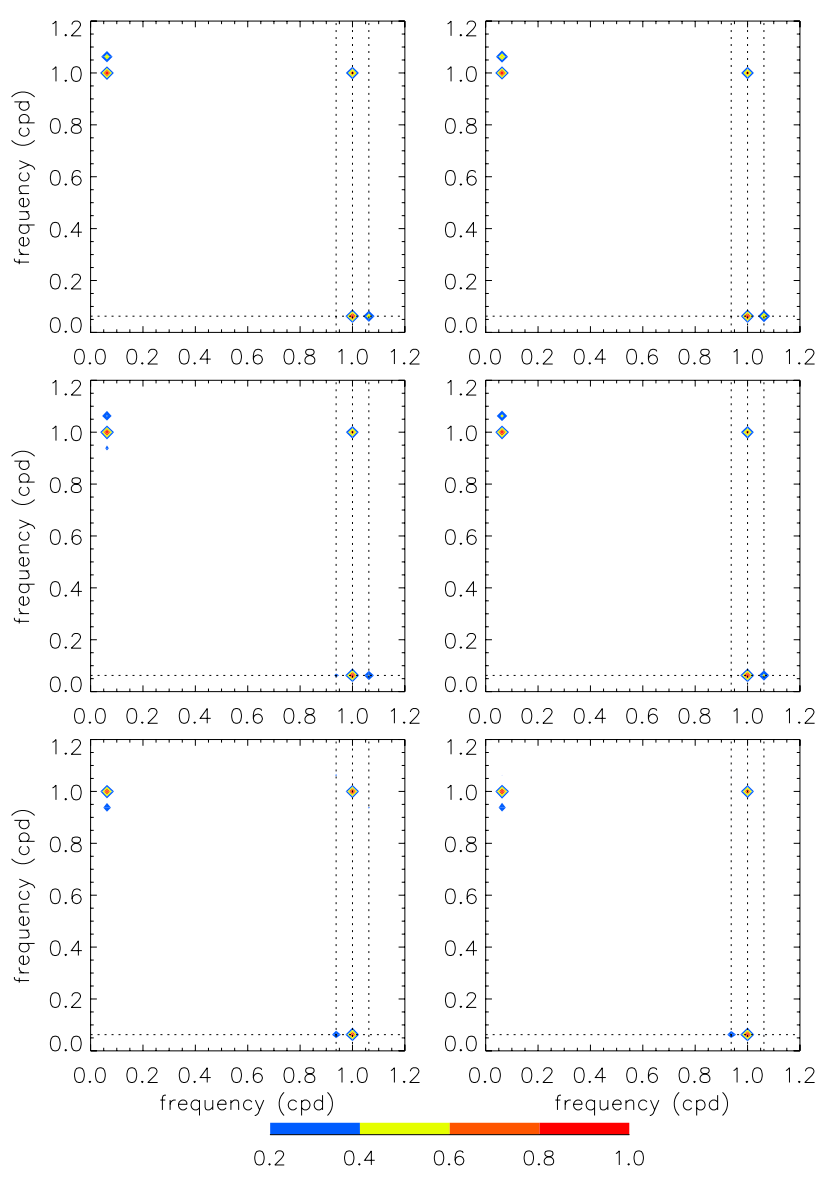

Fig. 6. Normalized bispectrum. The dotted horizontal line represents the 16-day wave, and the dotted vertical lines from left to right represent the 25.6, 24 and 22.59-h waves, respectively. The left column denotes the normalized bispectrum at $90 \mathrm{~km}$ (bottom), $92 \mathrm{~km}$ (middle) and $94 \mathrm{~km}$ (top), and the right column denotes the normalized bispectrum at $91 \mathrm{~km}$ (bottom), $93 \mathrm{~km}$ (middle) and $95 \mathrm{~km}$ (top), respectively.

As we expected, the amplitude of the diurnal tide is intensely modulated at the 16-day period.

In addition, there is the other strong peak at $(1.0,1.0$, 2.0) cpd, which could result from the possible nonlinear interaction between the diurnal and semidiurnal tides, and may also be attributed to the phase consistency due to their common forcing.

\section{Summary}

A strong nonlinear interaction between the 16-day wave and the diurnal tide is studied based on Maui meteor radar observations during the period from 10 November to 11 December 2003. The observation shows that the activity of a strong 16-day wave with meridional amplitudes between 14.3 and $18.5 \mathrm{~m} \mathrm{~s}^{-1}$ at heights of $90-95 \mathrm{~km}$ lasts for 32 days. The phase of the 16-day wave propagates downward slowly, 


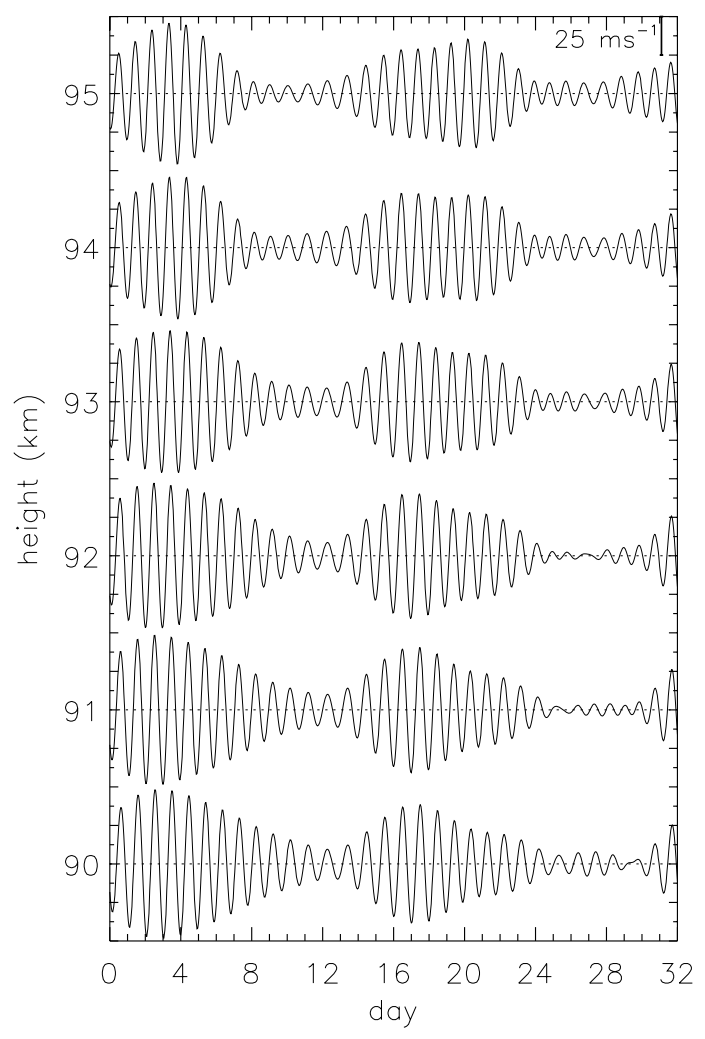

Fig. 7. Diurnal tide derived from band-pass filter with high and low cut-off frequencies corresponding to periods at 21.33 and $27.43 \mathrm{~h}$.

and its amplitude increases in the weak eastward background zonal wind but decreases in the weak westward zonal flow, which is consistent with the theoretical and previous observational studies.

The sum and difference interactions between the 16-day wave and the diurnal tide with different intensities are observed. The sum nonlinear interaction is quite strong, and the spectral strength of the secondary sum wave with a period of $22.59 \mathrm{~h}$ is larger than that of the diurnal tide. However, the spectrum of the secondary difference wave is hardly identified. The secondary sum wave beats with the diurnal tide, which leads to the intense modulation of the diurnal tide at period of 16 days. It is interesting that the secondary sum wave further interacts with the 16-day wave to generate a new secondary sum wave with a period of $21.33 \mathrm{~h}$. Such an interaction may be regarded as a third-order nonlinear interaction between the 16-day wave and the diurnal tide with two-step interaction.

Huang et al. (2013a) studies the third-order nonlinear interaction of atmospheric gravity waves. The features of the third-order interaction for gravity waves, including energy transfer direction, energy exchange strength, and frequency and wavenumber relationships among the interacting waves, are revealed, and the two kinds of third-order nonlinear interactions of gravity waves are clarified. Since the third-order interaction between the 16-day wave and the diurnal tide occurred in this event, the third-order nonlinear interaction of atmospheric waves may arise significantly in the MLT region. However, because it is difficult to accurately separate the diurnal tide and the generated waves from the observational wind owing to their close frequencies, we cannot discuss more properties of the second- and third-order interactions between the 16-day wave and the diurnal tide in detail. The nonlinear interactions between planetary waves and tides are still in need of further investigation through observations and models in the future.

Acknowledgements. The authors would like to thank the editor and anonymous reviewers for their comments on the manuscript. This work was jointly supported by the National Natural Science Foundation of China through grants 41074110, 41174133 and 41221003; the National Basic Research Program of China (grant 2012CB825605); and the Ocean Public Welfare Scientific Research Project, State Oceanic Administration, People's Republic of China (No. 201005017).

Topical Editor C. Jacobi thanks two anonymous referees for their help in evaluating this paper.

\section{References}

Babu, V. S., Kumar, K. K., John, S. R., Subrahmanyam, K. V., and Ramkumar, G.: Meteor radar observations of short-term variability of quasi 2 day waves and their interaction with tides and planetary waves in the mesosphere-lower thermosphere region over Thumba $\left(8.5^{\circ} \mathrm{N}, 77^{\circ} \mathrm{E}\right)$, J. Geophys. Res., 116, D16121, doi:10.1029/2010JD015390, 2011.

Beard, A. G., Mitchell, N. J., Williams, P. J. S., and Kunitake, M.: Non-linear interactions between tides and planetary waves resulting in periodic tidal variability, J. Atmos. Sol. Terr. Phy., 61, 363376, 1999.

Chang, L. C., Palo, C. E., and Liu, H.-L.: Short-term variability in the migrating diurnal tide caused by interactions with the quasi 2 day wave, J. Geophys. Res., 116, D12112, doi:10.1029/2010JD014996, 2011.

Charney, J. G. and Drazin, P. G.: Propagation of planetary-scale disturbances from lower into the upper atmosphere, J. Geophys. Res., 66, 83-109, 1961.

Day, K. A. and Mitchell, N. J.: The 16-day wave in the Arctic and Antarctic mesosphere and lower thermosphere, Atmos. Chem. Phys., 10, 1461-1472, doi:10.5194/acp-10-1461-2010, 2010.

Dickinson, R. E.: Planetary Rossby waves propagating vertically through weak westerly wind wave guides, J. Atmos. Sci., 25, 984-1002, 1968.

Dickinson, R. E.: Theory of planetary wave-zonal flow interaction, J. Atmos. Sci., 26, 73-81, 1969.

Espy, P. J. and Witt, G.: Observation of a quasi 16-day oscillation in the polar summer mesospheric temperature, Geophys. Res. Lett., 23, 1071-1074, 1996.

Espy, P. J., Stegman, J., and Witt, G.: Interannual variations of the quasi-16-day oscillation in the polar summer mesospheric temperature, J. Geophys. Res., 102, 1983-1990, 1997. 
Fritts, D. C. and Vincent, R. A.: Mesospheric momentum flux studies at Adelaide, Australia: observations and a gravity wave-tidal interaction model, J. Atmos. Sci., 44, 605-619, 1987.

Franke, S. J., Chu, X., Liu, A. Z., and Hocking, W. K.: Comparison of meteor radar and $\mathrm{Na}$ Doppler lidar measurements of winds in the mesosphere region above Mauii, Hawaii, J. Geophys. Res., 110, D09S02, doi:10.1029/2003JD004486, 2005.

Forbes, J. M. and Leveroni, S.: Quasi-16-day oscillation in the ionosphere, Geophys. Res. Lett., 19, 981-984, 1992.

Forbes, J. M., Hagan, M. E., Miyahara, S., Vial, F., Manson, A. H., Meek, C. E., and Portnyagin, Y. I.: Quasi-16-day oscillation in the mesosphere and lower thermosphere, J. Geophys. Res., 100, 9149-9163, 1995.

Gurubaran, S., Sridharan, S., Ramkumar, T. K., and Rajaram, R.: The mesospheric quasi-2-day wave over Tirunelveli $\left(8.71^{\circ} \mathrm{N}\right), \mathrm{J}$. Atmos. Sol. Terr. Phy., 63, 975-985, 2001.

Harris, T. J. and Vincent, R. A.: The quasi 2-day wave observed on the equatorial middle atmosphere, J. Geophys. Res., 98, 1048110490, 1993.

Hartmann, D. L., Mechoso, C. R., and Yamazaki, K.: Observations of Wave-Mean Flow Interaction in the Southern Hemisphere, J. Atmos. Sci., 41, 351-362, 1984.

Hecht, J. H., Walterscheid, R. L., Gelinas, L. J., Vincent, R. A., Reid, I. M., and Woithe, J. M.: Observations of the phaselocked 2 day wave over the Australian sector using mediumfrequency radar and airglow data, J. Geophys. Res., 115, D16115, doi:10.1029/2009JD013772, 2010.

Hocking, W. K., Fuller, B., and Vandepeer, B.: Real-time determination of meteor-related parameters utilizing modern digital technology, J. Atmos. Sol. Terr. Phy., 63, 155-169, 2001.

Huang, C., Zhang, S. D., Zhou, Q., Yi, F., and Huang, K. M.: Atmospheric waves and their interactions in the thermospheric neutral wind as observed by the Arecibo incoherent scatter radar, J. Geophys. Res., 117, D19105, doi:10.1029/2012JD018241, 2012.

Huang, K. M., Zhang, S. D., and Yi, F.: Gravity wave excitation through resonant interaction in a compressible atmosphere, Geophys. Res. Lett., 36, L01803, doi:10.1029/2008GL035575, 2009.

Huang, K. M., Zhang, S. D., and Yi, F.: Reflection and transmission of atmospheric gravity waves in a stably sheared horizontal wind field, J. Geophys. Res., 115, D16103, doi:10.1029/2009JD012687, 2010.

Huang, K. M., Zhang, S. D., Yi, F., Huang, C. M., Gan, Q., Gong, Y., and Zhang, Y. H.: Third-order resonant interaction of atmospheric gravity waves, J. Geophys. Res.-Atmos., 118, 21972206, doi:10.1002/jgrd.50252, 2013a.

Huang, K. M., Liu, A. Z., Lu, X., Li, Z., Gan, Q., Gong, Y., Huang, C. M., Yi, F., and Zhang, S. D.: Nonlinear coupling between quasi 2 day wave and tides based on meteor radar observations at Maui, J. Geophys. Res.-Atmos., 118, 10936-10943, doi:10.1002/jgrd.50872, 2013b.

Jacobi, Ch.: 6 year mean prevailing winds and tides measured by VHF meteor radar over Collm $\left(51.3^{\circ} \mathrm{N}, 13.0^{\circ} \mathrm{E}\right)$, J. Atmos. Sol. Terr. Phy., 78, 8-18, 2012.

Jacobi, Ch., Schminder, R., and Kürschner, D.: Non-linear interaction of the quasi 2-day wave and long-term oscillations in the summer midlatitude mesopause region as seen from LF D1 wind measurements over Central Europe (Collm, $\left.52^{\circ} \mathrm{N}, 15^{\circ} \mathrm{E}\right)$, J. Atmos. Sol. Terr. Phy., 60, 1175-1191, 1998.
Jacobi, Ch., Portnyagin, Y. I., Merzlyakov, E. G., Kashcheyev, B. L., Oleynikov, A. N., Kürschner, D., Mitchell, N. J., Middleton, H. R., Muller, H. G., and Comley, V. E.: Mesosphere/lower thermosphere wind measurements over Europe in summer 1998, J. Atmos. Sol. Terr. Phy., 63, 1017-1031, 2001.

Jacobi, Ch., Fröhlich, K., and Pogoreltsev, A.: Quasi two-day-wave modulation of gravity wave flux and consequences for the planetary wave propagation in a simple circulation model, J. Atmos. Sol. Terr. Phy., 68, 283-292, 2006.

Jiang, G. Y., Xiong, J. G., Wan, W. X., Ning, B. Q., Liu, L. B., Vincent, R. A., and Reid I.: The 16-day waves in the mesosphere and lower thermosphere over Wuhan $\left(30.6^{\circ} \mathrm{N}, 114.5^{\circ} \mathrm{E}\right)$ and Adelaide $\left(35^{\circ} \mathrm{S}, 138^{\circ} \mathrm{E}\right)$, Adv. Space Res., 35, 2005-2010, 2005.

Kamalabadi, F., Forbes, J. M., Makarov, N. M., and Portnyagin, Y. I.: Evidence for nonlinear coupling of planetary waves and tides in the Antarctic mesopause, J. Geophys. Res., 102, 4437-4446, 1997.

Kim, Y. C. and Powers, E. J.: Digit bispectral analysis and its application to nonlinear wave interactions, IEEE Trans. Plasma Sci., PS 7, 120-131, 1979.

Kumar, K. K., Deepa, V., Antonita, M., and Ramkumar, G.: Meteor radar observations of short-term tidal variabilities in the low-latitude mesosphere-lower thermosphere: Evidence for nonlinear wave-wave interactions, J. Geophys. Res., 113, D16108, doi:10.1029/2007JD009610, 2008.

Leovy, C. B., Sun, C.-R., Hitchman, M. H., Remsberg, E. E., Russell, J. M., Gordley, L. L., Gille, J. C., and Lyjak, L. V.: Transport of Ozone in the Middle Stratosphere: Evidence for Planetary Wave Breaking, J. Atmos. Sci., 42, 230-244, 1985.

Li, T., She, C. Y., Liu, H.-L., Yue, J., Nakamura, T., Krueger, D. A., Wu, Q., Dou, X. K., and Wang, S.: Observation of local tidal variability and instability, along with dissipation of diurnal tidal harmonics in the mesopause region over Fort Collins, Colorado $\left(41^{\circ} \mathrm{N}, 105^{\circ} \mathrm{W}\right)$, J. Geophys. Res., 114, D06106, doi:10.1029/2008JD011089, 2009.

Lima, L. M., Batista, P. P., Clemasha, B. R., and Takahashi, H.: 16day wave observed in the meteor winds at low latitudes in the southern hemisphere, Adv. Space Res., 38, 2615-2620, 2006.

Lindzen, R. S.: Turbulence and stress owing to gravity wave and tidal breakdown, J. Geophys. Res., 86, 9707-9714, 1981.

Liu, A. Z., Roble, R. G., Hecht, J. H., Larsen, M. F., and Gardner, C. S.: Unstable layers in the mesopause region observed with Na lidar during the Turbulent Oxygen Mixing Experiment (TOMEX) campaign, J. Geophys. Res., 109, D02S02, doi:10.1029/2002JD003056, 2004.

Liu, H.-L. and Hagan, M. E.: Local heating/cooling of the mesosphere due to gravity wave and tidal coupling, Geophys. Res. Lett., 25, 2941-2944, 1998.

Liu, H.-L., Li, L., She, C. Y., Oberheide, J., Wu, Q., Hagan, M. E., Xu, J., Roble, R. G., Mlynczak, M. G., and Russell III, J. M.: Comparative study of short-term diurnal tidal variability, J. Geophys. Res., 112, D18108, doi:10.1029/2007JD008542, 2007.

Liu, X., Xu, J., Liu, H.-L., and Ma, R.: Nonlinear interactions between gravity waves with different wavelengths and diurnal tide, J. Geophys. Res., 113, D08112, doi:10.1029/2007JD009136, 2008.

Lu, X., Liu, A. Z., Oberheide, J., Wu, Q., Li, T., Li, Z., Swenson, G. R., and Franke, S. J.: Seasonal variability of the diurnal tide in the mesosphere and lower thermosphere over Maui, 
Hawaii $\left(20.7^{\circ} \mathrm{N}, 156.3^{\circ} \mathrm{W}\right)$, J. Geophys. Res., 116, D17103, doi:10.1029/2011JD015599, 2011.

Luo, Y., Manson, A. H., Meek, C. E., Meyer, C. K., and Forbes, J. M.: Quasi 16-day oscillations in the mesosphere and lower thermosphere at Saskatoon $\left(52^{\circ} \mathrm{N}, 107^{\circ} \mathrm{W}\right), 1980-1996$, J. Geophys. Res., 105, 2125-2138, 2000.

Luo, Y., Manson, A. H., Meek, C. E., Meyer, C. K., Burrage, M. D., Fritts, D. C., Hall, C. M., Hocking, W. K., MacDougall, J., Riggin, D. M., and Vincent, R. A.: The 16-day planetary waves: multi-MF radar observations from the arctic to equator and comparisons with the HRDI measurements and the GSWM modelling results, Ann. Geophys., 20, 691-709, doi:10.5194/angeo20-691-2002, 2002a.

Luo, Y., Manson, A. H., Meek, C. E., Thayaparan, T., MacDougall, J., and Hocking, W.: The 16-day Wave in the Mesosphere and Lower Thermosphere: Simultaneous Observations at Saskatoon $\left(52^{\circ} \mathrm{N}, 107^{\circ} \mathrm{W}\right)$ and London $\left(43^{\circ} \mathrm{N}, 81^{\circ} \mathrm{W}\right)$, Canada, J. Atmos. Sol. Terr. Phy., 64, 1287-1307, 2002b.

McCormack, J. P., Eckermann, S. D., Hoppel, K. W., and Vincent, R. A.: Amplification of the quasi-two day wave through nonlinear interaction with the migrating diurnal tide, Geophys. Res. Lett., 37, L16810, doi:10.1029/2010GL043906, 2010.

McDonald, A. J., Hibbins, R. E., and Jarvis, M. J.: Properties of the quasi 16 day wave derived from EOS MLS observations, J. Geophys. Res., 116, D06112, doi:10.1029/2010JD014719, 2011.

McLandress, C.: The seasonal variation on the propagating diurnal tide in the mesosphere and lower thermosphere. Part II: The role of tidal heating and zonal mean zonal winds, J. Atmos. Sci., 59, 907-921, 2002.

Mitchell, N. J., Middleton, H. R., Beard, A. G., Williams, P. J. S., and Muller, H. G.: The 16-day planetary wave in the mesosphere and lower thermosphere, Ann. Geophys., 17, 1447-1456, doi:10.1007/s00585-999-1447-9, 1999.

Miyahara, S., Yoshida, Y., and Miyoshi, Y.: Dynamic coupling between the lower and upper atmosphere by tides and gravity waves, J. Atmos. Terr. Phys., 55, 1039-1053, 1993.

Miyoshi, Y.: Numerical simulation of the 5-day and 16-day waves in the mesopause region, Earth Planet. Space, 51, 763-772, 1999.

Nakamura, T., Fritts, D. C., Isler, J. R., Tsuda, T., Vincent, R. A., and Reid, I. M.: Short-period fluctuations of the diurnal tide observed with low-latitude MF and meteor radars during CADRE: Evidence for gravity wave/tidal interactions, J. Geophys. Res., 102, 26225-26238, 1997.

Namboothiri, S. P., Kishore, P., and Igarashi, K.: Climatological studies of the quasi 16-day oscillations in the mesosphere and lower thermosphere at Yamagawa $\left(31.2^{\circ} \mathrm{N}, 130.6^{\circ} \mathrm{E}\right)$, Japan, Ann. Geophys., 20, 1239-1246, doi:10.5194/angeo-20-12392002, 2002.

Norton, W. A. and Thuburn, J.: Sensitivity of mesospheric mean flow, planetary waves, and tides to strength of gravity wave drag, J. Geophys. Res., 104, 30897-30911, doi:10.1029/1999JD900961, 1999.

Palo, S. E., Roble, R. G., and Hagan, M. E.: Middle atmosphere effects of the quasi-two wave from a General Circulation Model, Earth Planet. Space, 51, 629-647, 1999.

Palo, S. E., Forbes, J. M., Zhang, X., Russell, J. M., and Mlynczak, M. G.: An eastward propagating two-day wave: Evidence for nonlinear planetary wave and tidal coupling in the mesosphere and lower thermosphere, Geophys. Res. Lett., 34, L07807, doi:10.1029/2006GL027728, 2007.

Pancheva, D. V.: Evidence for nonlinear coupling of planetary waves and tides in the lower thermosphere over Bulgaria, J. Atmos. Sol. Terr. Phy., 62, 115-132, 2000.

Pancheva, D. V.: Quasi-2-day wave and tidal variability observed over Ascension Island during January/February 2003, J. Atmos. Sol. Terr. Phy., 68, 390-407, 2006.

Pancheva, D. V. and Mitchell, N. J.: Planetary waves and variability of the semidiurnal tide in the mesosphere and lower thermosphere over Esrange $\left(68^{\circ} \mathrm{N}, 21^{\circ} \mathrm{E}\right)$ during winter, J. Geophys. Res., 109, A08307, doi:10.1029/2004JA010433, 2004.

Pancheva, D. V., Beard, A. G., and Mitchell, N. J.: Nonlinear interactions between planetary waves in the mesosphere/lowerthermosphere region, J. Geophys. Res., 105, 157-170, 2000a.

Pancheva, D., Mukhtarov, P., Mitchell, N. J., Beard, A. G., and Muller, H. G.: A comparative study of winds and tidal variability in the mesosphere/lower-thermosphere region over Bulgaria and the UK, Ann. Geophys., 18, 1304-1315, doi:10.1007/s00585000-1304-3, 2000b.

Pancheva, D. V., Merzlyakov, E., Mitchell, N. J., Portnyagin, Y., Manson, A. H., Jacobi, Ch., Meek, C. E., Luo, Y., Clark, R. R., Hocking, W. K., MacDougall, J., Muller, H. G., Kürschner, D., Jones, G. O. L., Vincent, R. A., Reid, I. M., Singer, W., Igarashi, K., Fraser, G. I., Fahrutdinova, A. N., Stepanov, A. M., Poole, L. M. G., Mailga, S. B., Kashcheyev, B. L., and Oleynikov, A. N.: Global-scale tidal variability during the PSMOS campaign of June-August 1999: Interaction with planetary waves, J. Atmos. Sol. Terr. Phy., 64, 1865-1896, 2002.

Phillips, O. M.: On the dynamics of unsteady gravity waves of finite amplitude, J. Fluid Mech., 9, 193-217, 1960.

Polvani, L. M. and Saravanan, R.: The three-dimensional structure of breaking Rossby waves in the polar wintertime stratosphere, J. Atmos. Sci., 57, 3663-3685, 2000.

Rüster, R.: VHF radar observations of nonlinear interactions in the summer polar mesosphere, J. Atmos. Terr. Phys., 56, 1289-1299, 1994.

Salby, M. L.: Rossby normal modes in nonuniform background configurations. Part II: Equinox and solstice conditions, J. Atmos. Sci., 38, 1827-1840, 1981.

Salby, M. L.: Sampling theory for asynoptic satellite observations. Part I: Space-time spectra, resolution, and aliasing, J. Atmos. Sci., 39, 2577-2600, 1982a.

Salby, M. L.: Sampling theory for asynoptic satellite observations. Part II: Fast Fourier synoptic mapping, J. Atmos. Sci., 39, 26012614, 1982b.

Salby, M. L.: Survey of planetary-scale traveling waves: The state of theory and observations, Rev. Geophys., 22, 209-236, 1984.

Stenflo, L.: Resonant three-wave interactions in plasmas, Phys. Scr., T50, 15-19, 1994.

Stenflo, L. and Shukla, P. K.: Nonlinear acoustic-gravity waves, J. Plasma Phys., 75, 841-847, 2009.

Teitelbaum, H. and Vial, F.: On tidal variability induced by nonlinear interaction with planetary waves, J. Geophys. Res., 96, 14169-14178, 1991.

Thayaparan, T., Hocking, W. K., and MacDougall, J.: Amplitude, phase, and period variations of the quasi 2-day wave in the mesosphere and lower thermosphere over London, Canada $\left(43^{\circ} \mathrm{N}\right.$, 
$\left.81^{\circ} \mathrm{W}\right)$, during 1993 and 1994, J. Geophys. Res., 102, 94619478, 1997.

Walterscheid, R. L. and Vincent, R. A.: Tidal generation of the phase-locked 2 day wave in the southern hemisphere summer by wave-wave interactions, J. Geophys. Res., 101, 26567-26576, 1996.

Williams, C. R. and Avery, S. K.: Analysis of long-period waves using the mesosphere-stratosphere-troposphere radar at Poker Flat, Alaska, J. Geophys. Res., 97, 20855-20861, 1992.

Xu, J., Smith, A. K., Collins, R. L., and She, C.: Signature of an overturning gravity wave in the mesospheric sodium layer: Comparison of a nonlinear photochemical-dynamical model and lidar observations, J. Geophys. Res., 111, D17301, doi:10.1029/2005JD006749, 2006.
Xu, J., Smith, A. K., Liu, H.-L., Yuan, W., Wu, Q., Jiang, G., Mlynczak, M. G., Russell, J. M., and Franke, S. J.: Seasonal and quasi-biennial variations in the migrating diurnal tide observed by Thermosphere, Ionosphere, Mesosphere, Energetics and Dynamics (TIMED), J. Geophys. Res., 114, D13107, doi:10.1029/2008JD011298, 2009.

Yue, J., Liu, H.-L., and Chang, L. C.: Numerical investigation of the quasi 2 day wave in the mesosphere and lower thermosphere, $\mathrm{J}$. Geophys. Res., 117, D05111, doi:10.1029/2011JD016574, 2012.

Zhou, Q. H., Monroy, H., Fritts, D. C., Ierkic, H. M., Isham, B., Isler, J. R., and Palo, S. E.: Radar observation of longitudinal variability of tidal/planetary waves and mean motions in the tropical mesosphere, J. Geophys. Res., 105, 2151-2161, 2000. 